\title{
Framework of Blockchain-Supported E-Commerce Platform for Small and Medium Enterprises
}

\author{
Ji Jiang * and Jin Chen
}

\footnotetext{
check for updates

Citation: Jiang, J.; Chen, J.

Framework of Blockchain-Supported E-Commerce Platform for Small and Medium Enterprises. Sustainability 2021, 13, 8158. https://doi.org/ $10.3390 /$ su13158158
}

Academic Editors: Samuel Adomako and Albert Danso

Received: 28 June 2021

Accepted: 20 July 2021

Published: 21 July 2021

Publisher's Note: MDPI stays neutral with regard to jurisdictional claims in published maps and institutional affiliations.

Copyright: (c) 2021 by the authors. Licensee MDPI, Basel, Switzerland. This article is an open access article distributed under the terms and conditions of the Creative Commons Attribution (CC BY) license (https:// creativecommons.org/licenses/by/ $4.0 /)$.
School of Information Technology and Management, University of International Business and Economics, Beijing 100029, China; chenjin@uibe.edu.cn

* Correspondence: jiangjispe@126.com

\begin{abstract}
Small and medium enterprises (SMEs) play an important role in promoting the national economy and providing employment opportunities. E-commerce platforms may facilitate transactions between these enterprises. However, transactions on the e-commerce platform are non-face-toface, strongly virtual, and variable, resulting in SMEs often facing moral hazards and opportunistic behaviors. Blockchain is a distributed ledger consisting of an encryption algorithm, consensus mechanism, and smart contracts, having the characteristics of authenticity, security, transparency, and unforgeability. Thus, the problems faced by SMEs can be resolved by combining e-commerce platforms and blockchain technology. In this study, we first provide a conceptual framework for blockchain-supported e-commerce platforms for SMEs. Second, based on this conceptual framework, we build a total business architecture. Finally, we propose three key applications to illustrate how the platform facilitates SMEs in solving financing and trading problems. This study provides significant guidance for the operation and management of blockchain-supported e-commerce platforms for these enterprises.
\end{abstract}

Keywords: blockchain technology; small and medium enterprises; e-commerce platform

\section{Introduction}

Small and medium enterprises (SMEs) are the mainstay of the modern national economy, and they are numerous and widely distributed [1-3]. These enterprises have made outstanding contributions to the economic development of all countries, especially developing countries [4,5]. According to statistics, SMEs account for $90 \%$ of businesses and provide more than $50 \%$ of employment positions worldwide. In addition, about $40 \%$ of the national income of emerging economies comes from formal SMEs. It has been estimated that SMEs create seven out of ten jobs in emerging markets [6]. These data show that SMEs play an irreplaceable role in promoting economic growth and creating jobs; however, they have the characteristics of small-scale operation, poor stability, weak brand influence, and defective data management, which bring them financing and transactions problems. Specifically, an imperfect financial system results in financing issues for SMEs, and information asymmetry causes transaction matching and tracking problems.

To solve the financing problems faced by SMEs, there are many financing methods related to supply chain finance (SCF), such as accounts receivable financing, prepayment financing, and inventory financing [7-9]. However, these financing methods require financial institutions to take considerable effort in verifying the authenticity of bills and check the status of collateral, which increases the cost of enterprise financing [10-12]. There are a number of e-commerce platforms for SMEs that facilitate transactions between these enterprises [13-15], such as Alibaba (Hangzhou, China), GlobalSources (Hong Kong, China), and Amazon Business (Washington, DC, USA). However, transactions on the e-commerce platform are non-face-to-face, strongly virtual, and variable, and the transaction matching and tracking problems faced by SMEs are still difficult to solve. In general, SMEs face three major development problems when they trade on the e-commerce platform. 
First, when SMEs apply for loans from financial institutions, these institutions prefer to charge SMEs more interest for loans compared with large enterprises, to offset the high default risk of SMEs; this is because SMEs have poor risk resistance capacity and imperfect financial systems. Second, it is difficult for SMEs to match appropriate trading partners in the trading process owing to the asymmetric information of buyers and sellers and insufficient market influence; this is embodied in the fact that the seller's supply capacity and the buyer's demand for goods cannot be matched perfectly. Finally, SMEs usually face challenges as a result of moral hazards and opportunistic behaviors in the transaction process, as transaction information is easy to alter and difficult to track.

Blockchain is a distributed ledger consisting of an encryption algorithm, a consensus mechanism, and smart contracts, which have the characteristics of authenticity, unforgeability, and traceability $[16,17]$. Based on our study and analysis results, we consider blockchain technology a suitable choice for solving the problems faced by SMEs. The combinations of blockchain and e-commerce platforms in previous studies are outlined in Table 1. The chain structure of blockchain ensures the authenticity and transparency of data [18]. Thus, financial institutions can use these data to evaluate the credit of enterprises without tedious bill confirmation and collateral management, which reduces financing costs. Wang et al. proposed a new credit pattern that allows banks to assess the credit of SMEs through the blockchain technology [19]. Moreover, it is easy to confirm responsibility when moral hazards and opportunistic behaviors occur in the trading process because all transaction data are accurately recorded on the blockchain [20]. Cai and Choi combine blockchain with the clothing rental platform to overcome the opportunistic behavior of retailers [21]. The encryption algorithm of blockchain addresses the contradiction between data privacy protection and information sharing requirements $[22,23]$. Hence, the buyer and seller can obtain data on the chain for making decisions and matching transactions. Van et al. designed an e-commerce platform based on blockchain to reduce information asymmetry [24]. The smart contract of blockchain ensures the automatic execution of transactions based on presupposed conditions [25], which improves the efficiency of the transactions and avoids a malicious breach of contract. Nayak and Dhaigude built a blockchain-supported e-commerce platform to ensure the safety and efficiency of transactions [26].

Table 1. The combinations of blockchain and e-commerce platforms.

\begin{tabular}{ccc}
\hline Blockchain & \multicolumn{1}{c}{ Description } & Reference \\
\hline Chain structure & $\begin{array}{c}\text { The chain structure of blockchain ensures the } \\
\text { authenticity and transparency of data. }\end{array}$ & {$[18-21]$} \\
\hline Encryption algorithm & $\begin{array}{c}\text { The encryption algorithm of blockchain addresses } \\
\text { the contradiction between data privacy protection } \\
\text { and information sharing requirements. }\end{array}$ & {$[22-24]$} \\
\hline Smart contract & $\begin{array}{l}\text { The smart contract of blockchain ensures the } \\
\text { automatic execution of transactions based on } \\
\text { presupposed conditions. }\end{array}$ & {$[25,26]$} \\
\hline
\end{tabular}

Given the aforementioned analysis, the combination of e-commerce platforms and blockchain technology is suitable for solving the problems faced by SMEs. However, few studies have focused on the details of this combination. In this study, we first provide a conceptual framework for a blockchain-supported e-commerce platform for SMEs. Second, based on this conceptual framework, we build the total business architecture, which is composed of application scenarios, platform services, and a distributed ledger shared by all nodes. Finally, we propose three key applications to illustrate how the platform facilitates SMEs to solve financing and trading problems, namely enterprise financing, transaction matching, and transaction tracking. To the best of our knowledge, this study is an initial work that combines blockchain technology with an e-commerce platform for SMEs to solve the financing and transaction problems of these enterprises. The remainder of this paper is organized as follows. Section 2 presents a literature review. Section 3 provides a conceptual 
framework for a blockchain-supported e-commerce platform for SMEs. Section 4 builds the total business architecture and proposes three key applications of this platform. Section 5 discusses how this platform solves the financing and transaction problems. Section 6 concludes this study and presents future research directions.

\section{Literature}

In this section, we review the literature related to this research, including SME financing, platform operations, and blockchain technology.

\subsection{SME Financing}

SME financing is an important source of enterprise funds [27,28]; however, SMEs find it difficult and costly to obtain financing owing to unsound financial information, weak risk resistance, and insufficient innovation ability [29,30]. Currently, financing problems have seriously restricted the development of SMEs. To alleviate the current financing dilemma, many studies have proposed innovative financing methods, especially in supply chain finance. There are three main financing methods: accounts receivable financing, prepayment financing, and inventory financing [31-33]. Accounts receivable financing refers to an enterprise utilizing accounts receivable as collateral to apply for loans from banks [31]. The loan amount is generally $50-90 \%$ of the face value of the accounts receivable. The enterprise transfers accounts receivable to the bank and informs the buyer to return the arrears to the bank. Prepayment financing occurs when the buyer applies for a short-term loan from the bank on the basis of the prepayment generated by the real trade contract [32]. The loan enterprise takes its sales revenue as the first source of repayment to the bank. This can help enterprises solve the capital bottleneck in the procurement process. Inventory financing refers to an enterprise taking the goods stored in the warehouse (generally designated by the bank) as a guarantee to apply for loans from banks [33]. These financing methods require enterprises to provide collateral or bills to prove their repayment ability; moreover, financial institutions need to verify and keep collaterals and bills, which adds to the workload of banks and the borrowing cost of SMEs.

\subsection{Platform Operations}

Platform operations have developed rapidly in recent times. The use of e-commerce platforms to facilitate SMEs' trade has been studied in the literature. E-commerce platforms embrace a large number of SMEs and provide customized services to these enterprises. As mentioned earlier, SMEs play an important role in promoting the development of the national economy, and a variety of e-commerce platforms for SMEs have been proposed [34-36]. However, e-commerce platforms cannot guarantee the authenticity of information; hence, SMEs usually face the threat of counterfeit products in the transaction process. Experts and scholars have proposed relevant solutions to address the problem of fake products, such as product quality inspection, delayed payment, and product security code. Some scholars have proposed a product-quality inspection mechanism. The buyer carries out professional technical inspections of goods after receiving the products. When the product passes the spot check, the buyer pays for the goods and completes the transaction $[37,38]$. The delayed payment mechanism means that the downstream dealers transfer the payment to the manufacturer after consumers use the goods successfully $[39,40]$. In addition to product quality inspection and delayed payment, the product anti-counterfeiting code is the most effective means of resisting counterfeit products in the supply chain [41-43]. Krishna and Dugar used two-dimensional codes as quick response codes to prove the authentication of products, which reduces the difficulty of encoding and decoding the quick response code [41]. Wazid et al. proposed an anticounterfeiting system based on near-field communication to verify the authenticity of pharmaceutical products [42]. Shaik developed a product anti-counterfeiting method by combining encryption technology and matrix two-dimensional code with website services, which can reduce the detection cost and improve the anti-counterfeiting accuracy [43]. At present, 
enterprises often generate additional product labels to ensure product authenticity; nevertheless, these labels face the problem of cloning and counterfeiting in the circulation process of public systems.

\subsection{Blockchain Technology}

Blockchain was first proposed by Nakamoto in 2008 as the underlying supporting technology of Bitcoin [44]. The basic technologies of blockchain consist of encryption algorithms, consensus mechanisms, and smart contracts, which ensure that blockchain technology has the characteristics of authenticity, security, transparency, and unforgeability $[16,17]$. Given the characteristics of blockchain, blockchain technology has been applied to supply chain management. First, the chain structure of the blockchain ensures the authenticity and immutability of data, which makes the entire transaction data traceable [18]. Lin et al. used blockchain technology to develop a food management platform that realized the effective tracking of commodities under the premise of ensuring data privacy [45]. Creydt et al. pointed out that the origin and planting mode of agricultural products are important factors in determining the price of goods. They used blockchain to record and track all the information of agricultural products, which effectively avoided the problem of product counterfeiting [46]. Second, the encryption algorithm solves the contradiction between data privacy protection and information-sharing requirements [22,23]. Nodes on the blockchain are able to access data on the chain to make appropriate decisions, which breaks the data island and realizes information sharing. Rejeb et al. combined the Internet of Things and blockchain technology to record and supervise transaction data, which achieved data security sharing and privacy protection [47]. Dwivedi et al. proposed a blockchain system to coordinate commodity transportation and inventory management. This system provides accurate and reliable information to help enterprises make better supply chain decisions [48]. In addition, the intelligent contract automatically processes the transaction according to presupposed conditions, which reduces the human communication cost, improves transaction efficiency, and effectively avoids all kinds of opportunism and moral hazards [49-51].

These studies show that blockchain technology can be used to solve the problem of supply chain management as SMEs also face similar problems. However, past research has paid little attention to combining blockchain technology with e-commerce platforms for SMEs. Therefore, this study builds a conceptual framework for blockchainsupported e-commerce platforms for SMEs; moreover, we propose three key applications to illustrate how the platform facilitates SMEs to solve financing and trading problems. This research provides significant guidance to platform managers attempting to build blockchain-supported e-commerce platforms for SMEs.

\section{Conceptual Framework}

To solve the problems faced by SMEs, we propose a conceptual framework that combines blockchain technology and e-commerce platforms. It is generally recognized that blockchain can be divided into public, consortium, and private blockchain. A public blockchain is fully decentralized as each node is able to join or exit the blockchain network at will, which results in serious privacy problems and reduces the speed of transactions. A private blockchain, however, is totally centralized as it is controlled by an independent organization; therefore, nodes can only join the blockchain network with the permission of the central organization. A consortium blockchain is controlled by specific nodes, and these nodes can verify, store, and update data in the blockchain network. Compared with public and private blockchains, consortium blockchain has a higher transaction processing speed, and the setting of authority of nodes is more flexible. Therefore, we applied a consortium blockchain to build our platform. There are four types of participants in the platform: enterprises, financial institutions, third-party logistics (3PL) providers, and regulators. We illustrate these nodes and the conceptual framework in detail in this section. 


\subsection{Nodal Types}

The blockchain-supported e-commerce platform for SMEs includes four types of nodes. These nodes share data through the platform, as shown in Figure 1.

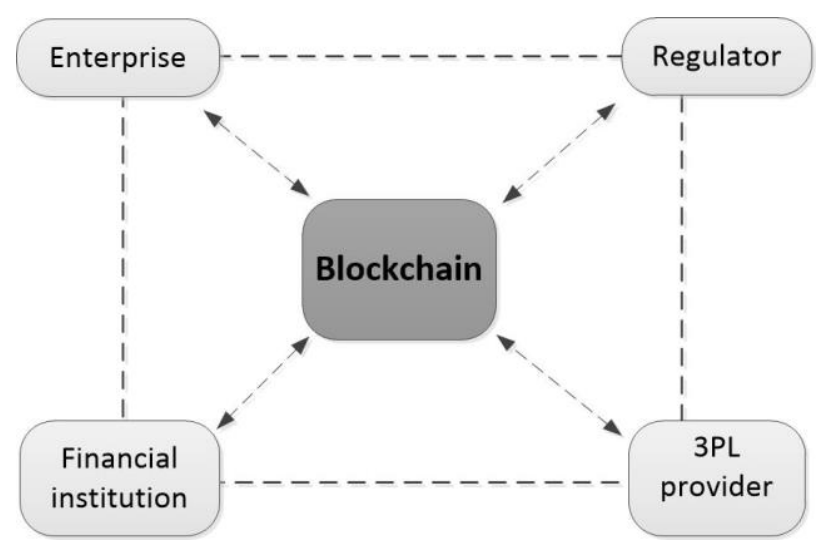

Figure 1. Node types.

\section{(1) Enterprise}

Enterprises refer to SMEs, which are the transaction subjects in the platform, including suppliers and retailers. In the blockchain-supported e-commerce platform, all enterprises need to upload relevant qualification information to the blockchain, and the blockchain records the historical transaction information of these enterprises. The chain structure ensures data authenticity and unforgeability; thus, financial institutions can use these data to evaluate the credit of SMEs without tedious manual confirmation steps. Moreover, the platform facilitates transactions between suppliers and retailers with the help of an intelligent matching algorithm. Transaction information is recorded in the blockchain and cannot be altered. Hence, it is possible for enterprises to track goods and logistics information. In addition, the transparency of these data reduces the opportunistic behavior of enterprises.

\section{(2) 3PL provider}

3PL providers offer logistics services for SMEs on platforms such as transportation, warehousing, inventory management, and commodity management. In addition to regular logistics support, 3PL enterprises collect inventory information and commodity logistics status, and then update the data to the blockchain platform in real time. These data are significant when SMEs conduct enterprise financing and transaction tracking on an e-commerce platform. Financial institutions evaluate the credit of SMEs and make accurate decisions based on inventory information. Suppliers and retailers can track commodity logistics status at any time, which increases the trust of both parties and ensure the authenticity of the transaction.

\section{(3) Financial institution}

Financial institutions are banks that evaluate SMEs' credit and provide financial support for enterprises. In the traditional model, banks tend to evaluate enterprises with financial data to reduce their default risk of loan enterprises. However, the financial data of SMEs are defective, which implies that these enterprises face difficulties accessing loans from banks. In addition, owing to information asymmetry between enterprises and banks, banks need to invest a lot of human and material resources to verify the authenticity of information, which increases the difficulty of audit and the cost of lending. In the blockchain-supported e-commerce platform, blockchain records relevant information of enterprises, including enterprise qualification information, historical transaction data, order status, and inventory information. More importantly, the data in the blockchain are authentic, traceable, and unforgeable. Banks evaluate the credit of SMEs based on 
reliable non-financial data, which reduces the cost of financial institutions and improves the credibility of the results.

(4) Regulator

Regulators refer to government regulatory agencies such as the industry and commerce bureau and tax bureau. In our model, we apply a consortium blockchain to build an e-commerce platform. Regulators are specific nodes in the consortium blockchain that are responsible for reviewing the entry of new nodes and assigning node permission levels.

\subsection{Conceptual Framework}

The blockchain framework can be divided into six layers: the data, network, consensus, incentive, contract, and application layers. Based on this framework, we build a conceptual framework of a blockchain-supported e-commerce platform. SMEs join the blockchainsupported platform for enterprise financing, transaction matching, and transaction tracking rather than obtaining certain rewards. Consequently, there is no incentive layer in the framework. The conceptual framework of the blockchain-supported e-commerce platform is shown in Figure 2.

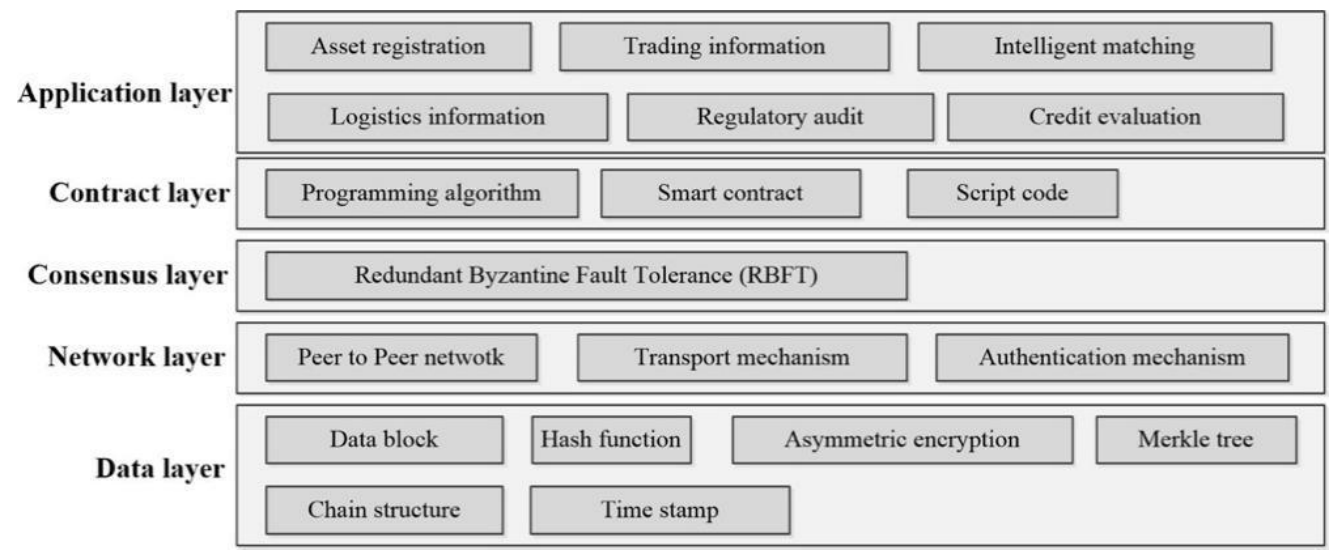

Figure 2. Conceptual framework.

The conceptual framework consists of five layers. The data layer is the underlying data structure of the blockchain, which includes the data block, chain structure, hash function, asymmetric encryption, time stamp, and Merkle tree. It can realize data storage and ensure the security of accounts and transactions. The network layer consists of a Peer to Peer (P2P) network, a transport mechanism, and an authentication mechanism. It carries out information changes between the blockchain nodes, and these nodes communicate by maintaining a common blockchain structure. The consensus layer is composed of a consensus algorithm and consensus mechanism, which enables highly dispersed nodes to reach consensus in a decentralized network. We choose redundant Byzantine fault tolerance (RBFT) as a consensus mechanism in consideration of the considerable number of SME nodes and frequent transactions of this platform. The contract layer encapsulates all types of scripts, codes, algorithms, and intelligent contracts, which enables automatic execution of instructions. The application layer is the most important layer of the framework, as it provides services for all nodes through the interface of this layer. The application layer consists of various application scenarios and cases. It includes asset registration, trading information, intelligent matching, logistics information, regulatory audit, and credit evaluation. The details of this layer are presented here.

\section{(1) Asset registration}

SMEs update their basic information to the platform through an asset registration module, which includes the registered capital of the enterprise, company type, qualification certificate, and other information. Regulators use these data to evaluate whether nodes can 
enter the platform to trade with other nodes. The enterprise registered successfully is able to accept the services provided by the platform.

\section{(2) Trading information}

Trading information consists of historical transaction data and the current transaction status. Historical transactions include the total number of transactions, transaction amounts, transaction receipts and bills, trading partners, default information, and other historical transaction details. Current transaction status includes order quantity and delivery date, payment amount and delivery date, and product information ranging from raw material processing to final product. These data recorded on the platform are transparent and unforgeable, so all nodes can access this information to make accurate judgments.

\section{(3) Intelligent matching}

Intelligent matching is one of the most crucial applications of the platform, which helps SMEs find the right partner with an intelligent matching algorithm. Suppliers update their product information, supply capacity, and selling price to this module. Retailers also update their product demand, expected price, and delivery date simultaneously. The intelligent matching algorithm calculates and provides matching results according to the supply and demand of the buyers and sellers.

(4) Logistics information

Logistics information is composed of inventory information and cargo transportation information, and it is collected by the 3PL provider. First, inventory management is important for the management of company information. Enterprises can easily manage inventory information by calling a logistics information module; moreover, inventory is a major collateral factor in enterprise financing. Financial institutions also check pledged goods over time through this module. More importantly, the buyer and seller can obtain cargo transportation information to confirm the status of transactions through the logistics information module.

(5) Regulatory audit

The regulatory audit module is responsible for checking the authenticity, compliance, and reliability of the data and tickets. Once the data and tickets are recorded on the platform, they cannot be changed; all nodes can access these data and tickets randomly. Therefore, all the data and tickets must be strictly audited before recording.

\section{(6) Credit evaluation}

The credit evaluation module takes charge of the credit evaluation for SMEs. Financial institutions, however, evaluate enterprises' credit before providing financial support for SMEs. On our platform, banks call credit evaluation modules to assess loan enterprises and grant loans to enterprises according to the assessment results. Enterprises, including buyers and sellers, usually face moral hazard and opportunistic behavior in the transaction process, as transactions on the e-commerce platform are non-face-to-face, strongly virtual, and variable. To ensure the reliability of transactions, the buyer and seller evaluate each other by calling the credit evaluation module, and the evaluation results are important bases for both sides of the transaction.

\section{Application of Blockchain-Supported E-Commerce Platform}

In the previous section, we introduced four types of nodes and proposed a conceptual framework for blockchain-supported e-commerce platforms. In light of node types and the conceptual framework, we provide the total business architecture, as shown in Figure 3. This architecture is composed of application scenarios, platform services, and distributed ledgers shared by all nodes. The characteristics of SMEs are that they are relatively small in scale, poor in stability, weak in brand influence, and defective in data management; thus, they face difficulties getting loans and commodity orders in the trading process. To solve the financing and trading problems faced by SMEs, this platform provides three 
key applications for these enterprises: enterprise financing, transaction matching, and transaction tracking. SMEs call platform services that include asset registration, trading information, intelligent matching, logistics information, regulatory audit, and credit evaluation to meet their financing and business requirements. Moreover, all nodes maintain a common distributed ledger, and they can access data according to their needs. Specifically, SMEs use different platform services and rely on data on distributed ledgers to realize different applications. The three main applications are described in detail here.

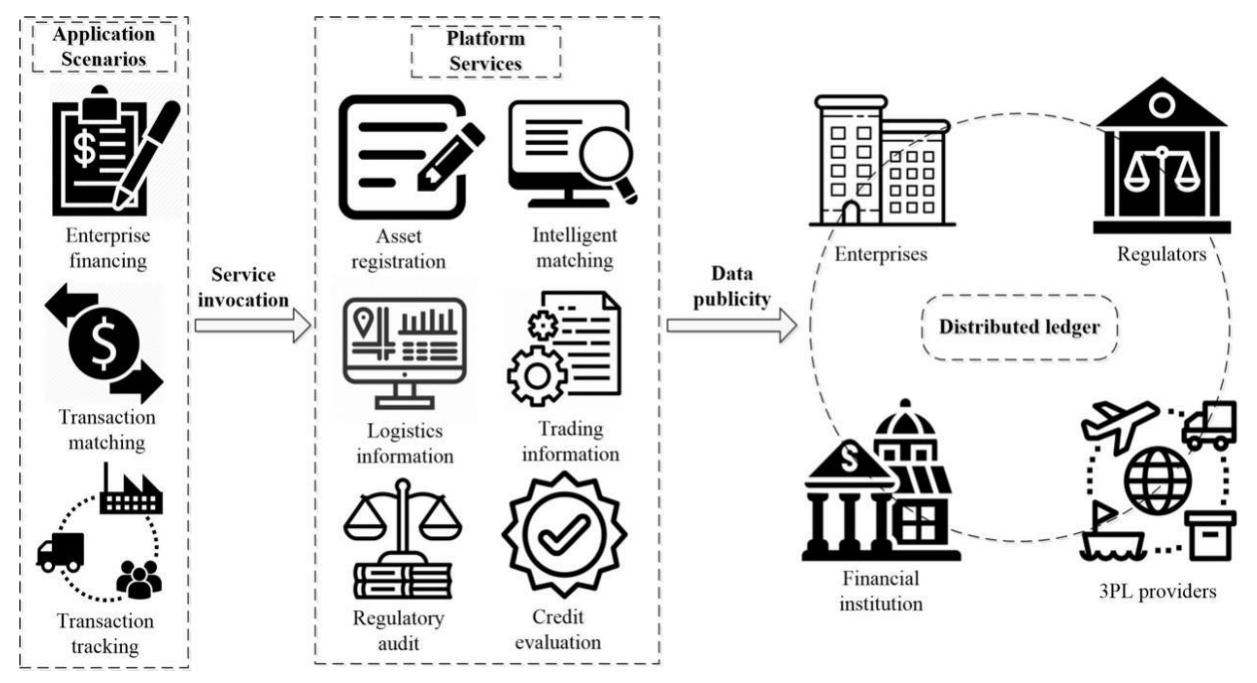

Figure 3. Business architecture.

\subsection{Enterprise Financing}

Currently, it is difficult and costly for SMEs to obtain financing from banks, as these enterprises are small in scale, incomplete in financial data, and unstable in development. Therefore, there are many financing methods to solve the economic difficulties of enterprises, such as accounts receivable financing, prepayment financing, and inventory financing, which require enterprises to provide collateral in the lending process. Our platform, supported by blockchain technology, ensures the authenticity, transparency, and unforgeability of trading information and logistics information, so this platform provides data financing for SMEs besides collateral financing. Specifically, data financing is different from collateral financing, and loan enterprises do not need to provide collateral to prove their repayment ability. In the process of data financing, banks evaluate loan enterprises using historical transaction data and logistics data, as shown in Figure 4.

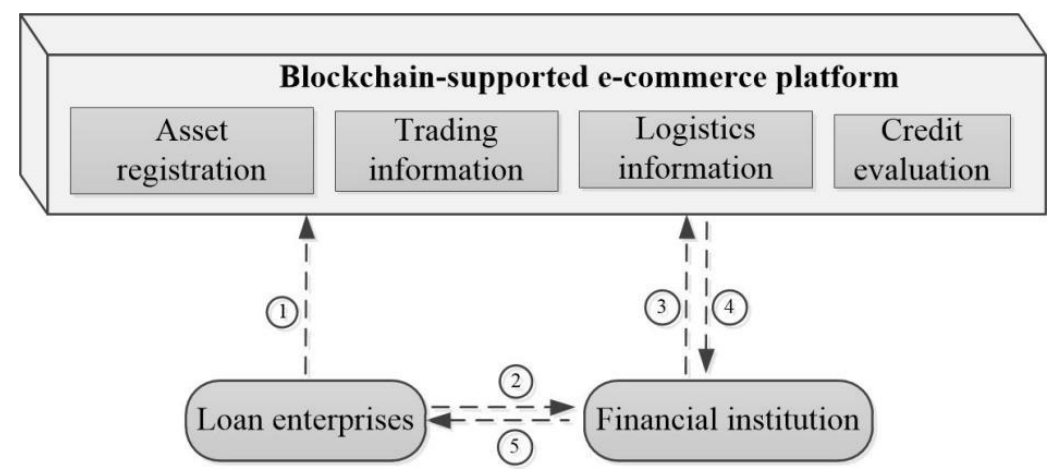

Figure 4. Data financing. 
(1) Loan enterprises call asset registration modules to submit their own enterprise qualification to the platform, which includes the registered capital of the enterprise, company type, qualification certificate, and other information. Moreover, with the dynamic adjustment of enterprises, they must constantly update their own data on the platform.

(2) In the process of development, enterprises encounter capital problems and apply for data financing from financial institutions.

(3) Financial institutions call the credit evaluation module to assess the credit of the loan enterprise.

(4) The credit evaluation module receives the assessment requirements of the bank. It evaluates the loan enterprise based on enterprise qualification information, historical transaction information, inventory information, and order information, and it returns the evaluation results to financial institutions.

(5) According to the evaluation results, financial institutions sign relevant loan contracts with loan enterprises and generate smart contracts according to the contracts. When the conditions of smart contracts are met, banks issue loans to enterprises. When an enterprise fails to fulfill its repayment obligations according to the contract, the smart contract will automatically suspend other business activities of the enterprise.

\subsection{Transaction Matching}

SMEs face the problem of transaction matching owing to information asymmetry and weak brand influence. On our platform, SMEs have the opportunity to match with suitable trading partners by calling on an intelligent matching module. Specifically, the intelligent matching algorithm compares the supply and demand of buyers and sellers and generates matching results to facilitate transactions between the two parties, as shown in Figure 5.

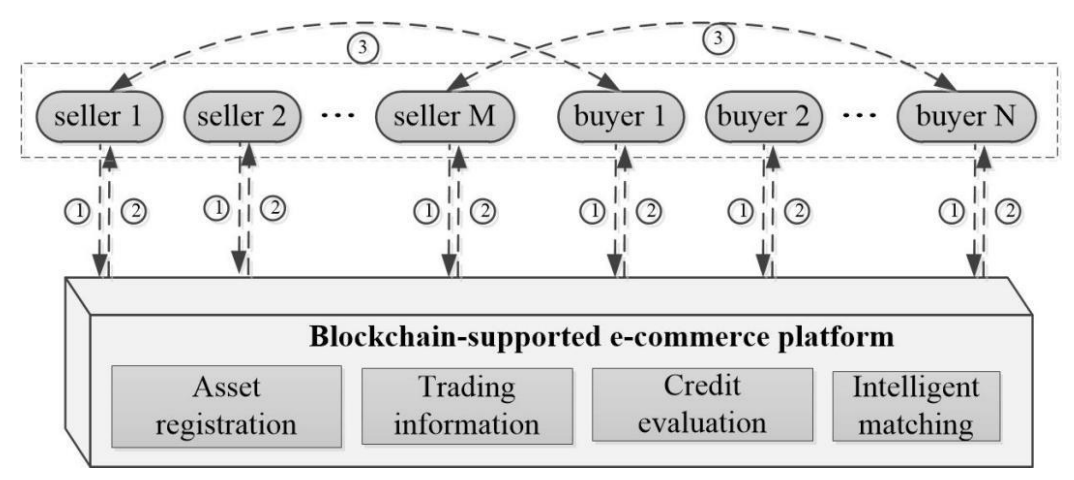

Figure 5. Transaction matching.

(1) SMEs call an asset-registration module to submit data. The buyer uploads the type, quantity, and expected price range of purchased goods, and the seller uploads the type, quantity, and price range of inventory goods.

(2) The transaction module calls the credit evaluation module to evaluate the ability of sellers and buyers, which mainly assesses the payment ability of buyers and the commodity supply ability of sellers in the transaction process. If the assessment result meets trading requirements, the intelligent matching algorithm compares the demand and supply of all parties, obtains the optimal matching scheme, and returns the results to the enterprise.

(3) The seller and buyer conclude the transaction contract according to the intelligent matching result and generate an intelligent contract according to the contract. When the conditions of the intelligent contract are met, the seller will automatically deliver the goods, and the buyer will submit the payment for goods to complete the transaction process. When the seller fails to provide the goods on time or the buyer fails to submit the payment as required, the smart contract will automatically suspend the later transaction of the seller or the buyer and upload the transaction results to the 
platform. Owing to data transparency and unforgeability, it will have a greater impact on the subsequent transaction of the enterprise, thereby compelling the enterprise to actively adhere to the terms of the contract and avoid opportunistic behaviors.

\subsection{Transaction Tracking}

SMEs trading on the e-commerce platform are always confronted with the product counterfeiting problem due to information asymmetry between the seller and buyer. Counterfeit products not only have a negative influence on the legal enterprises' income and brand reputation, but also seriously threaten the legitimate rights and interests of consumers. On our platform, the production and transportation information of goods are permanently recorded in detail on a distributed ledger and cannot be changed or deleted. Moreover, the sharing of data ensures that the seller checks whether the goods are genuine at any time; therefore, counterfeit products have no chance of entering the platform. The transaction-tracking process is shown in Figure 6.

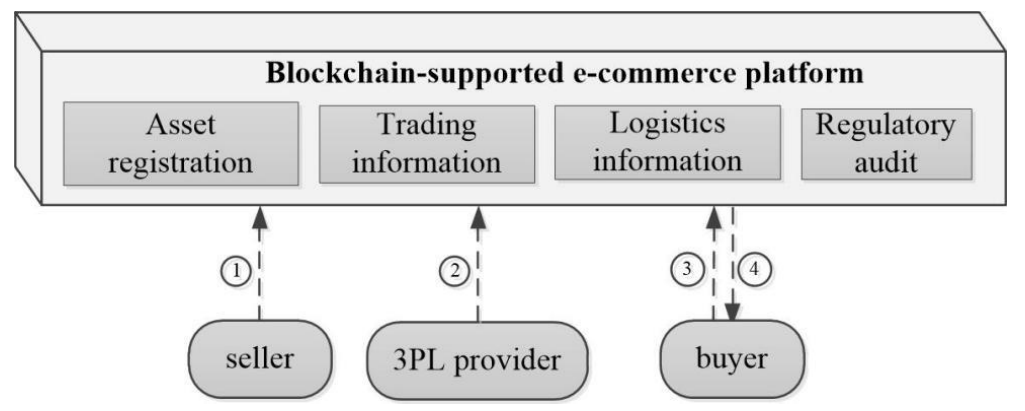

Figure 6. Transaction tracking.

(1) In the trading process, the seller uploads the production information to the platform, which includes raw material procurement, production link records, and final product packaging. The platform calls the regulatory audit module to identify the authenticity of the information, and these data are then submitted to the trading information module.

(2) The seller delivers final products to 3PL, which provides goods transportation and handover services between the buyer and seller. 3PL also uploads logistics information to the logistics information module during transportation.

(3) The sellers need to check the authenticity and legitimacy of the goods when they receive goods, so they apply to the platform to obtain product information.

(4) After receiving the application, the platform calls the transaction information module and logistics information module to access product information, and returns these data to the seller. According to these data, the seller decides whether the product meets contract requirements.

\section{Discussion}

SMEs have difficulty in enterprise financing, transaction matching, and tracking owing to the imperfect financial system and information asymmetry. Blockchain can ensure the authenticity, transparency, and unforgeability of data on the chain [16,17]. Specifically, the chain structure of the blockchain guarantees that the data are real, tamper-resistant, and traceable, which is instrumental in following up information in real time [18]. The encryption algorithm resolves the contradiction between data privacy protection and information sharing requirements, which breaks the information solitary island and passes information to all nodes on the blockchain to make accurate decisions [22,23]. Smart contracts automatically execute transactions based on presupposed conditions, which reduce the cost of human communication, improve transaction efficiency, and effectively avoid moral hazard and opportunistic behavior $[25,26]$. Therefore, the combination of e-commerce platforms for SMEs and blockchain technology is suitable for solving the problems faced by SMEs. 
In our study, we first provide a conceptual framework for a blockchain-supported e-commerce platform for SMEs. The platform includes four types of nodes, and these nodes share data through the platform. Enterprises are the main service subjects of the platform. The 3PL provider is responsible for providing logistics support, collecting inventory information and commodity logistics status, and updating data to the blockchain platform in real time. Financial institutions provide financial support to the enterprises. Regulators control the permission of enterprise nodes. Based on the framework of blockchain, we build the conceptual framework of the platform, which consists of the data layer, network layer, consensus layer, contract layer, and application layer. The difference between the framework of this platform and the framework of the blockchain is manifested in two aspects. On the one hand, we apply a consortium blockchain to build our platform and SMEs join the blockchain-supported platform for enterprise financing, transaction matching, and transaction tracking rather than obtaining certain rewards. Consequently, there is no incentive layer in the framework. On the other hand, the platform provides services for all nodes through the interface of the application layer. The application layer consists of asset registration, trading information, intelligent matching, logistics information, regulatory audit, and credit evaluation. SMEs update their basic information on the platform through an asset registration module. Trading information consists of historical transaction data and the current transaction status. Intelligent matching is one of the most crucial applications of the platform, which helps SMEs find the right partner with an intelligent matching algorithm. Logistics information is composed of inventory information and cargo transportation information, which is collected by the 3PL provider. The regulatory audit module is responsible for checking the authenticity, compliance, and reliability of the data and tickets. The credit evaluation module takes charge of the credit evaluation for SMEs.

Based on this conceptual framework, we built a total business architecture; moreover, we propose three key applications to illustrate how the platform facilitates SMEs to solve financing and trading problems, namely enterprise financing, transaction matching, and transaction tracking. First, this platform provides data financing for SMEs, which is different from collateral financing. Financial institutions assess the repayment ability and default risk of SMEs based on transaction and logistics data on the platform. Because of data authenticity and unforgeability on the platform, the evaluation results are reliable, and banks can rely on the evaluation results to provide loans to SMEs. With this financing method, enterprises have no need to submit collateral to financial institutions to prove repayment ability, and financial institutions do not have to spend considerable resources on verifying and keeping the collateral. Thus, it improves the evaluation efficiency, reduces the evaluation cost, and speeds up the lending process. Second, owing to information asymmetry and weak brand influence, SMEs have trouble in transaction matching. This platform provides transaction matching to SMEs. The buyer uploads the type, quantity, and expected price range of purchased goods, and the seller uploads the type, quantity, and price range of inventory goods. The intelligent matching algorithm then compares the demand and supply of all parties, obtains the optimal matching scheme, and returns the results to the enterprise. With transaction matching, the supply of the seller and the demand of the buyer achieve an appropriate match. It assists enterprises in making the best decisions and enhances transaction efficiency. Third, the platform facilitates enterprises to track transactions. The production and transportation information of goods are permanently recorded in detail on a distributed ledger and cannot be changed or deleted. It is easy to confirm the subject of responsibility when moral hazards and opportunistic behaviors occur during the trading process. Furthermore, the default behavior of enterprises will be permanently recorded on the platform, and other enterprises have the right to query the historical records of all enterprises, which encourages the enterprise to avoid malicious breach of contract and opportunistic behaviors. 


\section{Conclusions}

\subsection{Concluding Remarks}

SMEs make outstanding contributions to the national economy and provide employment opportunities. However, they have the characteristics of small-scale operation, poor stability, weak brand influence, and defective data management, which hinders their transactions and financing processes. Moreover, transactions on the e-commerce platform are non-face-to-face, strongly virtual, and variable, resulting in SMEs often facing moral hazards and opportunistic behaviors. Blockchain is a distributed ledger consisting of an encryption algorithm, consensus mechanism, and smart contract, which are authentic, unforgeable, and traceable. Thus, the problems faced by SMEs can be resolved by combining e-commerce platforms for these enterprises and blockchain technology. In this study, first, we provided a conceptual framework for a blockchain-supported e-commerce platform for SMEs. Second, based on this conceptual framework, we built a total business architecture. Finally, we proposed three key applications to illustrate how the platform facilitates SMEs in solving financing and trading problems: enterprise financing, transaction matching, and transaction tracking.

\subsection{Managerial Insights}

This study is an initial work that combines blockchain technology with e-commerce platforms for SMEs to solve the financing and transaction problems of these enterprises. This research provides significant guidance to platform managers attempting to build blockchain-supported e-commerce platforms for SMEs. However, some limitations hinder the development of blockchain-supported e-commerce platforms for SMEs. First, this platform collects and stores massive transaction and logistics data every day, which poses a threat to the application of blockchain. Moreover, the security and privacy of data are threatened because all nodes in the platform have access to data. Second, there is no incentive layer in our framework. Hence, all nodes except SMEs have little motivation to join the platform. The manager of the platform needs to solve these challenges in the process of platform deployment.

\subsection{Future Studies}

Although the combination of blockchain technology with e-commerce platforms can solve the financing and trading issues of SMEs, there are some unresolved problems. For example, it is difficult to guarantee the authenticity of data before they are recorded on the blockchain, which implies that all nodes are confronted with the threat of source data deception. Therefore, the manner of auditing the original data needs to be discussed in future research. Moreover, the application of blockchain helps solve the problems faced by SMEs, but it also increases the cost of enterprises simultaneously. Thus, future studies should focus on building models to evaluate the real effects of blockchain technology.

Author Contributions: Conceptualization, methodology, and software, J.J.; validation, J.J. and J.C.; formal analysis, investigation, resources, data curation, and writing-original-draft preparation, J.J.; writing-review and editing, J.J. and J.C. Both authors have read and agreed to the published version of the manuscript.

Funding: This research received no external funding.

Acknowledgments: We thank all the participants who assisted with the research.

Conflicts of Interest: The authors declare no conflict of interest.

\section{References}

1. Ayyagari, M.; Beck, T.; Demirguc-Kunt, A. Small and Medium Enterprises Across the Globe. Small Bus. Econ. 2007, 29, 415-434. [CrossRef]

2. Berisha, G.; Pula, J.S. Defining small and medium enterprises: A critical review. Acad. J. Bus. Adm. Law Soc. Sci. 2015, 1, 17-28.

3. Bigliardi, B.; Colacino, P.; Dormio, A.I. Innovative Characteristics of Small and Medium Enterprises. J. Technol. Manag. Innov. 2011, 6, 83-93. [CrossRef] 
4. Lee, S.; Park, G.; Yoon, B.; Park, J. Open innovation in SMEs-An intermediated network model. Res. Policy 2010, 39, 290-300. [CrossRef]

5. Rosenbusch, N.; Brinckmann, J.; Bausch, A. Is innovation always beneficial? A meta-analysis of the relationship between innovation and performance in SMEs. J. Bus. Ventur. 2011, 26, 441-457. [CrossRef]

6. World Bank. Small and Medium Enterprises Finance. Available online: https://www.worldbank.org/en/topic/smefinance (accessed on 18 November 2020).

7. Liu, W. Boosting SMEs with better and innovative financing services. J. Sys. Manag. Sci. 2014, 4, 15-23.

8. Hu, Y.; Wang, F. Research on financing model of the Chinese SMEs in supply chain finance. Int. J. Econ. Financ. Manag. Sci. 2016, 4, 235. [CrossRef]

9. Zhi, B.; Wang, X.; Xu, F. Impawn rate optimisation in inventory financing: A canonical vine copula-based approach. Int. J. Prod. Econ. 2020, 227, 107659. [CrossRef]

10. Mol-Gómez-Vázquez, A.; Hernández-Cánovas, G.; Koëter-Kant, J. Do foreign banks intensify borrower discouragement? The role of developed European institutions in ameliorating SME financing constraints. Int. Small Bus. J. Res. Entrep. 2019, 38, 3-20. [CrossRef]

11. Moscalu, M.; Girardone, C.; Calabrese, R. SMEs' growth under financing constraints and banking markets integration in the euro area. J. Small Bus. Manag. 2019, 58, 707-746. [CrossRef]

12. Di Carlo, F.; Mazzuto, G.; Bevilacqua, M.; Ciarapica, F. Retrofitting a Process Plant in an Industry 4.0 Perspective for Improving Safety and Maintenance Performance. Sustainability 2021, 13, 646. [CrossRef]

13. Huang, Y.; Chai, Y.; Liu, Y.; Shen, J. Architecture of next-generation e-commerce platform. Tsinghua Sci. Technol. 2019, 24, 18-29. [CrossRef]

14. Gonçalves, R.; Rocha, T.; Martins, J.; Branco, F.; Oliveira, M.A.-Y. Evaluation of e-commerce websites accessibility and usability: An e-commerce platform analysis with the inclusion of blind users. Univers. Access Inf. Soc. 2017, 17, 567-583. [CrossRef]

15. D'Adamo, I.; González-Sánchez, R.; Medina-Salgado, M.; Settembre-Blundo, D. E-Commerce Calls for Cyber-Security and Sustainability: How European Citizens Look for a Trusted Online Environment. Sustainability 2021, 13, 6752. [CrossRef]

16. Saberi, S.; Kouhizadeh, M.; Sarkis, J.; Shen, L. Blockchain technology and its relationships to sustainable supply chain management. Int. J. Prod. Res. 2018, 57, 2117-2135. [CrossRef]

17. Secinaro, S.; Calandra, D.; Biancone, P. Blockchain, trust, and trust accounting: Can blockchain technology substitute trust created by intermediaries in trust accounting? A theoretical examination. Int. J. Manag. Pract. 2021, 14, 129-145. [CrossRef]

18. Song, Q.; Chen, Y.; Zhong, Y.; Lan, K.; Fong, S.; Tang, R. A Supply-chain System Framework Based on Internet of Things Using Blockchain Technology. ACM Trans. Internet Technol. 2021, 21, 1-24. [CrossRef]

19. Wang, R.; Lin, Z.; Luo, H. Blockchain, bank credit and SME financing. Qual. Quant. 2019, 53, 1127-1140. [CrossRef]

20. Lorne, F.T.; Daram, S.; Frantz, R.; Kumar, N.; Mohammed, A.; Muley, A. Blockchain Economics and Marketing. J. Comput. Commun. 2018, 06, 107-117. [CrossRef]

21. Cai, Y.; Choi, T.; Zhang, J. Platform Supported Supply Chain Operations in the Blockchain Era: Supply Contracting and Moral Hazards*. Decis. Sci. 2020. [CrossRef]

22. Gao, F. Data encryption algorithm for e-commerce platform based on blockchain technology. Discret. Contin. Dyn. Syst. S 2019, 12, 1457-1470. [CrossRef]

23. Chen, L.; Lee, W.-K.; Chang, C.-C.; Choo, K.-K.R.; Zhang, N. Blockchain based searchable encryption for electronic health record sharing. Future Gener. Comput. Syst. 2019, 95, 420-429. [CrossRef]

24. Van Engelenburg, S.; Janssen, M.; Klievink, B. A Blockchain Architecture for Reducing the Bullwhip Effect. In International Symposium on Business Modeling and Software Design; Springer: Cham, Switzerland, 2018; pp. 69-82.

25. Yuan, R.; Xia, Y.-B.; Chen, H.-B.; Zang, B.-Y.; Xie, J. ShadowEth: Private Smart Contract on Public Blockchain. J. Comput. Sci. Technol. 2018, 33, 542-556. [CrossRef]

26. Ismanto, L.; Ar, H.S.; Fajar, A.N.; Sfenrianto; Bachtiar, S. Blockchain as E-Commerce Platform in Indonesia. J. Phys. Conf. Ser. 2019, 1179, 012114. [CrossRef]

27. Sensini, L.; Vazquez, M. Effects of Working Capital Management on SME Profitability: Evidence from an Emerging Economy. Int. J. Bus. Manag. 2021, 16, p85. [CrossRef]

28. Dai, R.M.; Kostini, N.; Tresna, P.W. The influence of financial attitude and financial literacy on behavioral finance: A study on leading small and medium enterprises in Cimahi City, Indonesia. Rev. Integrat. Bus. Econ. Res. 2021, 10, $322-329$.

29. Lu, Q.; Liu, B.; Yu, K. Effect of supplier-buyer cooperation on supply chain financing availability of SMEs. Int. J. Logist. Res. Appl. 2021, 1-19. [CrossRef]

30. Gupta, H.; Barua, M.K. A novel hybrid multi-criteria method for supplier selection among SMEs on the basis of innovation ability. Int. J. Logist. Res. Appl. 2017, 21, 201-223. [CrossRef]

31. Zhao, S.; Lu, X. Accounts Receivable Financing and Supply Chain Coordination under the Government Subsidy. In Proceedings of the International Conference on Information Science and Technology, Chengdu, China, 21-23 May 2021; pp. 477-484. [CrossRef]

32. Zhang, Y.; Li, X.; Wang, L.; Zhao, X.; Gao, J. Financing capital-constrained third-party logistic firms: Fourth party logistic driven financing mode vs. private lending driven financing mode. Int. J. Prod. Res. 2021, 1-20. [CrossRef]

33. Emtehani, F.; Nahavandi, N.; Rafiei, F.M. A joint inventory-finance model for coordinating a capital-constrained supply chain with financing limitations. Financ. Innov. 2021, 7, 1-39. [CrossRef] 
34. Wang, J.; Huang, P.; Zhao, H.; Zhang, Z.; Zhao, B.; Lee, D.L. Billion-Scale Commodity Embedding for E-commerce Recommendation in Alibaba. In Proceedings of the 24th ACM SIGKDD International Conference on Knowledge Discovery \& Data Mining, London, UK, 19-23 August 2018; pp. 839-848.

35. Ritala, P.; Golnam, A.; Wegmann, A. Coopetition-based business models: The case of Amazon.com. Ind. Mark. Manag. 2014, 43, 236-249. [CrossRef]

36. Fearnside, P. Business as usual: A resurgence of deforestation in the Brazilian Amazon. Yale Environ. 2017, 360, 1-6.

37. Baiman, S.; Fischer, P.E.; Rajan, M.V. Information, contracting, and quality costs. Manag. Sci. 2000, 46, 776-789. [CrossRef]

38. A Starbird, S. Penalties, rewards, and inspection: Provisions for quality in supply chain contracts. J. Oper. Res. Soc. 2001, 52, 109-115. [CrossRef]

39. Babich, V.; Tang, C. Managing Opportunistic Supplier Product Adulteration: Deferred Payments, Inspection, and Combined Mechanisms. Manuf. Serv. Oper. Manag. 2012, 14, 301-314. [CrossRef]

40. Rui, H.; Lai, G. Sourcing with Deferred Payment and Inspection under Supplier Product Adulteration Risk. Prod. Oper. Manag. 2015, 24, 934-946. [CrossRef]

41. Krishna, M.B.; Dugar, A. Product Authentication Using QR Codes: A Mobile Application to Combat Counterfeiting. Wirel. Pers. Commun. 2016, 90, 381-398. [CrossRef]

42. Wazid, M.; Das, A.K.; Khan, M.K.; Al-Ghaiheb, A.A.-D.; Kumar, N.; Vasilakos, A.V. Secure Authentication Scheme for Medicine Anti-Counterfeiting System in IoT Environment. IEEE Internet Things J. 2017, 4, 1634-1646. [CrossRef]

43. Shaik, C. Preventing Counterfeit Products using Cryptography, QR Code and Webservice. Comput. Sci. Eng. Int. J. 2021, 11, 1-11. [CrossRef]

44. Nakamoto, S. Bitcoin: A Peer-to-Peer Electronic Cash System. 2019. Available online: https://bitcoin.org/bitcoin.pdf (accessed on 11 February 2012).

45. Lin, Q.; Wang, H.; Pei, X.; Wang, J. Food Safety Traceability System Based on Blockchain and EPCIS. IEEE Access 2019, 7, 20698-20707. [CrossRef]

46. Creydt, M.; Fischer, M. Blockchain and more-Algorithm driven food traceability. Food Control 2019, 105, 45-51. [CrossRef]

47. Rejeb, A.; Keogh, J.G.; Treiblmaier, H. Leveraging the Internet of Things and Blockchain Technology in Supply Chain Management. Future Internet 2019, 11, 161. [CrossRef]

48. Dwivedi, S.K.; Amin, R.; Vollala, S. Blockchain based secured information sharing protocol in supply chain management system with key distribution mechanism. J. Inf. Secur. Appl. 2020, 54, 102554. [CrossRef]

49. Chang, S.E.; Chen, Y.-C.; Lu, M.-F. Supply chain re-engineering using blockchain technology: A case of smart contract-based tracking process. Technol. Forecast. Soc. Chang. 2019, 144, 1-11. [CrossRef]

50. Wang, S.; Li, D.; Zhang, Y.; Chen, J. Smart Contract-Based Product Traceability System in the Supply Chain Scenario. IEEE Access 2019, 7, 115122-115133. [CrossRef]

51. Dolgui, A.; Ivanov, D.; Potryasaev, S.; Sokolov, B.; Ivanova, M.; Werner, F. Blockchain-oriented dynamic modelling of smart contract design and execution in the supply chain. Int. J. Prod. Res. 2019, 58, 2184-2199. [CrossRef] 